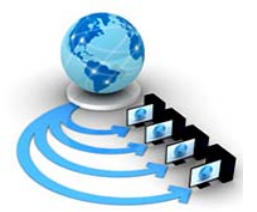

Volume 10, No. 6, November-December 2019

\title{
STUDY ON TEMPERATURE CHARACTERISTICS OF HIGH LOAD PRESS
}

\author{
Yanan QIN \\ Binzhou University \\ Binzhou, China
}

\begin{abstract}
Based on the finite element analysis software ABAQUS, the steady and transient temperature field of the high load press is analyzed, and the temperature field distribution characteristics of the ejector cylinder, the moving beam steel wire layer and the frame steel wire layer are obtained. The results show that the heat source can be effectively blocked by adding thermal insulation pad between the mold and the upper mold seat, which is better than the scheme of adding thermal insulation pad at both ends of the ejector cylinder, and the temperature control effect is obvious. The improvement of the surface heat transfer coefficient and the local surface heat transfer coefficient is not obvious for the improvement of the oil temperature.
\end{abstract}

Keywords: finite element analysis; high load press; temperature field; heat transfer

\section{INTRODUCTION}

High load press is the basic equipment for the production of large-scale die forgings such as integral bearing frame, turbine disk, etc. The core components of press frame, main cylinder, moving beam and so on adopt the technology of splitting and clamping, steel wire winding and pre tightening, which has the advantages of strong bearing capacity, high fatigue life and low cost compared with the integral casting structure $[1,2]$. In the welded structure, reliable pre tightening force of steel wire is of great significance to maintain the integrity of the frame and improve its fatigue resistance and reliability. Reliable hydraulic system is very important to ensure the safe operation of die forging press. As the energy transmission medium of hydraulic system, hydraulic oil has strict requirements on temperature and viscosity. If the temperature is too high, it will bring much harm, such as reducing the viscosity of hydraulic oil, serious leakage, reducing the system efficiency, serious oil oxidation, shortening the service life, poor lubrication of components, increasing wear and tear, and aging of seals [3].

The finite element software ABAQUS is used to analyze the steady and transient temperature field of the press and the temperature field distribution characteristics of key parts are studied. The simulation shows that the temperature rise of the ejector cylinder oil is too high, the local and overall heat dissipation coefficient is improved, and the effect of temperature rise is not obvious; two kinds of heat insulation design schemes are proposed, and the simulation verification is carried out, which proves that the scheme of adding heat insulation pad between the upper mold base and the mold is the best, which provides the basis for the application of the heat insulation design scheme in the project. The simulation results are basically consistent with the measured results of the temperature field, which verifies the finite element model.

\section{ESTABLISHMENT OF FINITE ELEMENT ANALYSIS MODEL}

\section{A. Geometric characteristics}

The press frame and moving beam body are respectively composed of 20 and 4 sub blocks which are combined and wound by steel wire, as shown in Fig.1. The two are connected by side $45^{\circ}$ guide rail pairs. The ejector cylinder is installed in the inner part of the moving beam lower base plate. Its function is to eject the forging from the upper die, and the lower base plate is connected with the upper die through the upper die base. In the process of die forging, on the one hand, due to the heat conduction between the upper die, the upper die seat and the lower base plate, the temperature rise of the steel wire layer of the ejector cylinder and the moving beam is obvious; on the other hand, due to the heat radiation effect, the temperature rise of the inner side of the column close to the die is also significant [4]. Therefore, it is of great significance for the safe and reliable operation of the equipment to calculate the temperature field of the steel wire layer in some sections of the frame, the steel wire layer of the moving beam and the ejector cylinder.

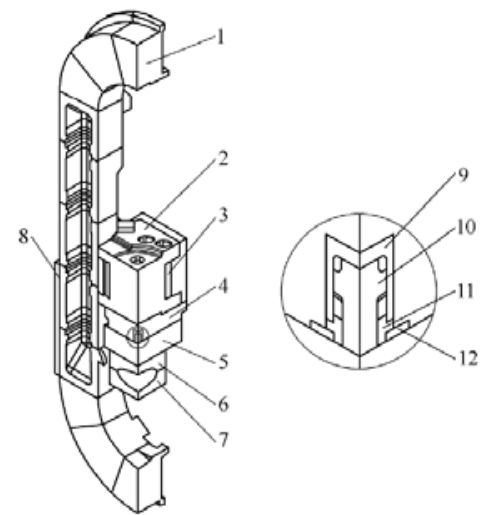

Fig.1 Geometric structure of the press

The press is composed of nearly one hundred assembly parts and thousands of single parts. The model needs to be reasonably simplified. The frame, moving beam, lower base plate, ejector cylinder, upper mold seat, mold and other relevant parts are modeled, simplified and cleaned. In order to study the temperature distribution of hydraulic oil in the ejector cylinder, the upper and lower cavity oil is approximately equivalent modeled. According to the symmetry of geometric model and boundary condition, 1 / 4 model is adopted [5].

\section{B. ABAQUS software introduction}

ABAQUS is a powerful finite element software for engineering simulation, which can solve problems from 
relatively simple linear analysis to many complex nonlinear problems ABAQUS includes a rich cell library that can simulate any geometry. It also has various types of material model library, which can simulate the performance of typical engineering materials, including metal, rubber, polymer materials, composite materials, reinforced concrete, compressible super elastic foam materials, and soil and rock materials. As a general simulation tool, ABAQUS can not only solve a large number of structural (stress / displacement) problems, but also simulate many problems in other engineering fields, such as heat conduction, mass diffusion, thermoelectric coupling analysis, acoustic analysis, geotechnical mechanics analysis (fluid permeability / stress coupling analysis) and piezoelectric media analysis.

ABAQUS provides users with a wide range of functions and is very simple to use. A large number of complex problems can be easily simulated by different combinations of option blocks. For example, the simulation of complex multicomponent problem is to combine the option block which defines the geometric size of each component with the corresponding material property option block. In most simulations, even for highly nonlinear problems, users only need to provide some engineering data, such as geometry, material properties, boundary conditions and load cases. In a nonlinear analysis, ABAQUS can automatically select the corresponding load increment and convergence limit. He can not only select the appropriate parameters, but also continuously adjust the parameters to ensure the accurate solution in the analysis process. Users can control the numerical calculation results well by defining parameters accurately [6].

\section{Finite element model}

Most parts in the assembly model are irregular, and dc3d4 four node linear heat transfer unit with strong adaptability is adopted [7]. Regular parts and key parts, such as moving beam, frame steel wire winding layer, ejection cylinder, etc., are adopted with high precision DC3D8 eight node linear heat transfer unit. The characteristic dimension of the frame element is $200 \mathrm{~mm}$, the moving beam, steel wire layer and ejector cylinder are $100 \mathrm{~mm}, 50 \mathrm{~mm}$ and $10 \mathrm{~mm}$ respectively. After discretization, the finite element model of the hydraulic press is obtained. The number of model nodes is 169 172, and the number of elements is 364081 .

In the die forging process of heavy press, large forgings can be regarded as the heat source in the system. The temperature field of press depends on the heat exchange process in the system composed of forging die press environment. The analysis of the temperature field of the press should focus on the radiation effect of the forging and die on the stand column section of the frame, and the heat conduction effect of the die on the upper die base, the lower base plate and the moving beam.

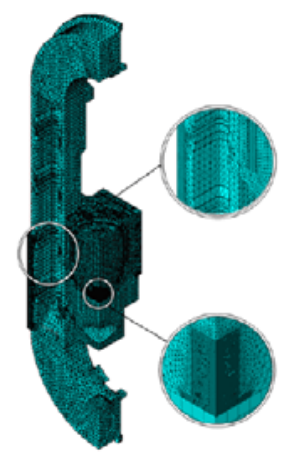

Fig.2 Mesh generation
Forging and die material, size, shape, forging temperature and forging process are diverse. The forging process is continuous, and the die absorbs and releases heat for many times continuously, and its temperature is always changing. These factors make it difficult to determine the initial conditions of simulation. Taking TC4 large frame hot die forging process as an example, the initial forging temperature of blank is given as $920{ }^{\circ} \mathrm{C}$, and the preheating (working) temperature of die is $300{ }^{\circ} \mathrm{C}$. The outer surface of die is far away from the heat source during continuous operation, and it is in the temperature drop area, and the heat absorption of upper die is small, and the actual surface temperature will be slightly lower than $300{ }^{\circ} \mathrm{C}$.

\section{IMULATION RESULTS AND ANALYSIS}

\section{A. Temperature field distribution}

Fig. 3 is the contour map of the temperature field distribution of the press under the condition of mold surface temperature of $300{ }^{\circ} \mathrm{C}$ (3D heat transfer is isothermal surface). Fig. 3 shows that the mold surface temperature is $300{ }^{\circ} \mathrm{C}$, and the temperature of the upper mold base is 93.9-297.4 ${ }^{\circ} \mathrm{C}$, the temperature of the lower base plate is $58.1-190.9{ }^{\circ} \mathrm{C}$, the temperature of the moving beam is $29.8-23.3{ }^{\circ} \mathrm{C}$, the maximum temperature of the moving beam steel wire layer is $86.2{ }^{\circ} \mathrm{C}$, and the super temperature is $29.8-23.3{ }^{\circ} \mathrm{C}$ The maximum temperature of stand column is $102.2{ }^{\circ} \mathrm{C}$, and the maximum temperature of steel wire layer is $39.6{ }^{\circ} \mathrm{C}$, which meets the design requirements. The maximum temperature is $187.6{ }^{\circ} \mathrm{C}$, which is located at the lower C-ring, and gradually reduces to $135.3{ }^{\circ} \mathrm{C}$ upward. The oil temperature of the lower cavity and the upper cavity far exceeds the allowable value of $70{ }^{\circ} \mathrm{C}$.

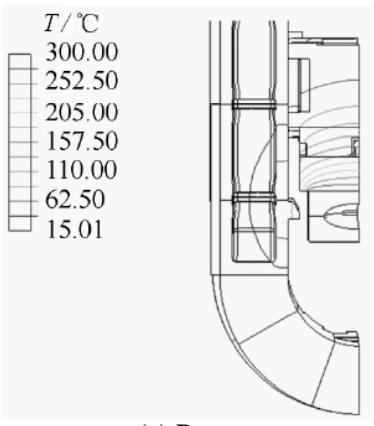

(a) Press

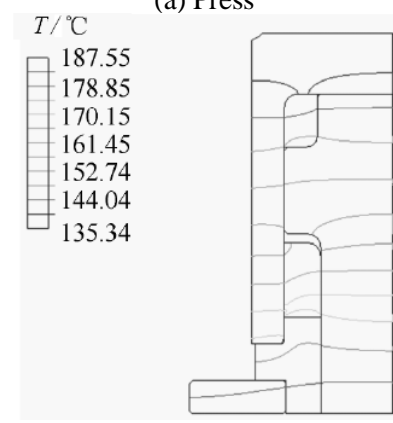

(b) Ejection cylinder

Fig.3 Contour map of the temperature field

\section{B. Maximum temperature}

Forging material, die forging process and other factors affect die temperature, change the initial boundary condition of die temperature, and study its influence on the temperature 
field of press, as shown in Fig.4. Fig.4 shows that the maximum temperature of column, moving beam steel wire and hydraulic oil increases with the increase of mold working temperature, the temperature of hydraulic oil and moving beam steel wire keeps linear relationship with mold temperature, and the relationship between column steel wire temperature and mold temperature is nonlinear. The reasons are analyzed. On the one hand, the heat transfer path from die, upper die seat, and lower base plate to moving beam is dominated by heat conduction. In the calculation, the material thermal conductivity, specific heat capacity and interface heat transfer coefficient are all approximately treated as constants, eliminating the influence of material nonlinearity and boundary nonlinearity in the heat transfer calculation, so the relationship between input and output is approximately linear; on the other hand, the die and frame are approximately linear The heat transfer between the columns is conducted by means of heat radiation, which results in a nonlinear relationship between the column steel wire and the mold temperature.

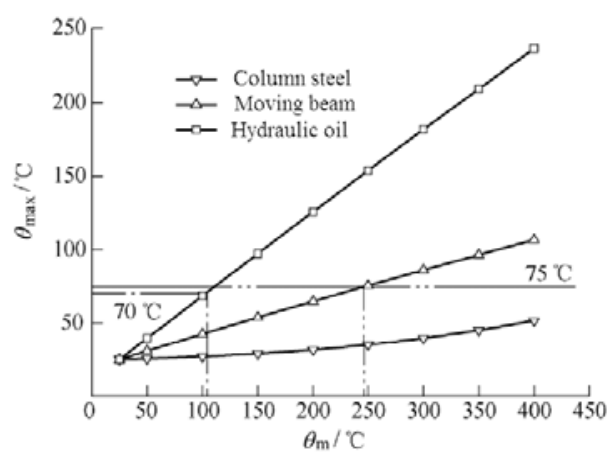

Fig.4 Maximum temperature at different mold temperature

It shows that the mold temperature is lower than $400{ }^{\circ} \mathrm{C}$, the column steel wire temperature is lower than $75{ }^{\circ} \mathrm{C}$, which always meets the design requirements. When the mold temperature is lower than $248{ }^{\circ} \mathrm{C}$, the moving beam steel wire temperature meets the requirements. Only when the mold temperature is lower than $105{ }^{\circ} \mathrm{C}$, the ejector cylinder oil temperature is lower than $70{ }^{\circ} \mathrm{C}$. When the normal mold working temperature is $300{ }^{\circ} \mathrm{C}$, the temperature reaches $181{ }^{\circ} \mathrm{C}$, which is far beyond the allowable value.

Because the normal working temperature of the hydraulic system is lower than $70{ }^{\circ} \mathrm{C}$, part of the heat will be taken away by the oil when the cylinder is ejected, which will reduce the temperature in the cylinder. However, the action time of the hydraulic cylinder is short. Most of them are in the state of retraction and locking. The heat exchange between the oil and the hydraulic system through the pipes, valves and the oil is very small, which is simplified as ignored. Steady state analysis is the final equilibrium state of temperature not changing with time, which is a kind of limit state, or it needs a long time to reach. Further transient analysis of heat transfer of press is carried out.

\section{Analysis results of transient temperature field of press}

According to the results of steady-state analysis, the transient analysis of die temperature is carried out at $100{ }^{\circ} \mathrm{C}$, $200{ }^{\circ} \mathrm{C}, 300{ }^{\circ} \mathrm{C}$ and $400{ }^{\circ} \mathrm{C}$. The curve shows that the temperature of the die is high, the slope value of the temperature time curve of steel wire and oil is large, the temperature rises fast, and the temperature value is high at the same time. For a single temperature rise curve, the slope of the initial curve is very small, the temperature rise is slow, the slope of the middle section is large and approximate constant, the slope of the latter section decreases again, and tends to its stable value with the time curve. This phenomenon can be explained by the change of temperature difference between the high and low temperature end of moving beam steel wire and hydraulic oil in the process of heat transfer.

Supplement the data points to get the curve of the relationship between the working time of the die and the temperature of the die, which meets the oil temperature of $70{ }^{\circ} \mathrm{C}$, as shown in Fig.5. When the mold temperature is $104{ }^{\circ} \mathrm{C}$, the steady-state temperature of the oil is $70{ }^{\circ} \mathrm{C}$, its working time can be extended indefinitely. In the range of $104-300{ }^{\circ} \mathrm{C}$, with the increase of the mold temperature, its working time drops sharply. Under the working condition of $300{ }^{\circ} \mathrm{C}$, it can only work for $8.4 \mathrm{~h}$ continuously. When the temperature is higher than $300{ }^{\circ} \mathrm{C}$, the working time changes smoothly. When the mold temperature reaches $700{ }^{\circ} \mathrm{C}$, the working time is $4.4 \mathrm{~h}$, further improving the temperature There was little change.

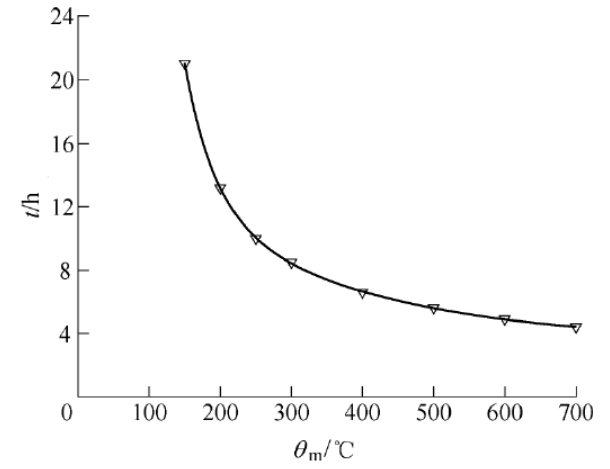

Fig.5 Relationship between continuous working time and mould temperature

The results of transient analysis show that the steel wire temperature of the moving beam can meet the design requirements and the oil temperature of the ejector cannot meet the requirements of long-term continuous operation. Therefore, the heat dissipation and insulation of the ejector should be considered in the structural design or tooling mold design of the press.

\section{Heat dissipation verification}

There are two ways to control the oil temperature of the ejector: one is to force the heat dissipation, improve the local heat dissipation conditions of the ejector or the overall heat dissipation conditions of the press, and speed up the heat dissipation; the other is to take heat insulation measures to block the heat flow from the mold to the ejector. Generally, water cooling can be considered for forced cooling, that is, cooling pipes are designed in the upper mold base, and cooling water is used for forced cooling. Because the thermal conductivity of water is more than 100 times that of air, the cooling effect is good, and the disadvantage is that the structure of the upper mold base is complex, the manufacturing cost is high, and there is additional energy consumption. In addition, it can also keep the structure of the upper mold base unchanged and use air cooling to force heat dissipation. The disadvantage is that the heat dissipation effect is poor and there is also additional energy consumption. Because the water-cooling scheme needs to modify the upper mold base structure, the manufacturing cost is high, and the additional energy consumption is large. 


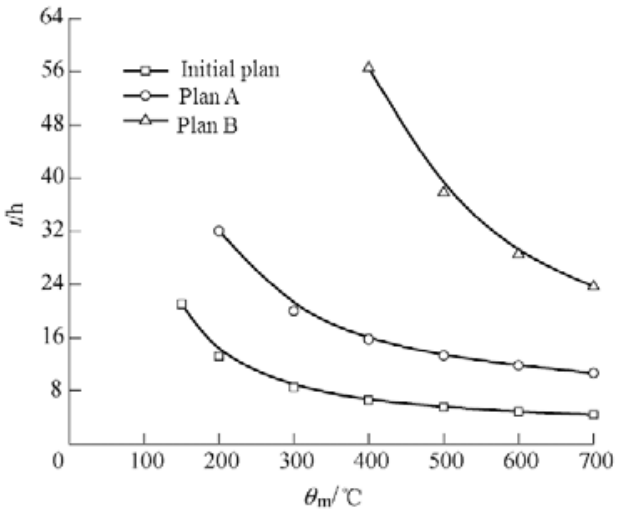

Fig.6 Relationship between continuous working time and mould temperature

Fig.6 shows the relationship between the continuous working time of the press and the mold temperature when the oil temperature is maintained at $70{ }^{\circ} \mathrm{C}$ in the initial design and insulation scheme a and $\mathrm{B}$. With the increase of surface heat transfer coefficient, the temperature of oil and steel wire decreases slightly, and the temperature changes little in the low temperature section. The increase of heat transfer coefficient on the local surface of cylinder has little effect on the temperature field of steel wire. The working time is extended from $8.4 \mathrm{~h}$ to $9 \mathrm{~h}$, so the effect of reducing oil temperature and prolonging working time is not obvious.

\section{CONCLUSION}

According to the simulation calculation results, in the actual production process of the high load press, the scheme of adding $10 \mathrm{~mm}$ asbestos heat insulation pad between the upper mold base and the mold is adopted. The scheme does not need to adjust the size chain of the ejector cylinder structure installation, which is convenient to implement. The heat insulation effect is good in practical application, effectively reducing the temperature of oil and steel wire, and ensuring the safe and reliable operation of the equipment.

\section{VI. ACKNOWLEDGEMENTS}

The paper is supported by the Research Fund Project of Binzhou University ( BZXYLG1908 ).

\section{REFERENCES}

[1] A.L. LU. "Present situation and development trend of high speed press,” China Mechanical Engineering, vol.12, pp.183-186, October 2011.

[2] X.W. LIU. "Structural design and strength analysis of pseudo-shunt extrusion die for cantilever aluminium alloy profiles,” Journal of Rock Mechanics and Engineering, vol.33, pp. 1432-144, May 2014.

[3] W. CHENG, Q.H. LIAO. "Application of 3d printing technology in mold manufacturing," Light Industry Machinery, vol.33, pp. 107-110, February 2015.

[4] Y. LI. "Research on key technology of die surface modification for flexible three-dimensional stretchbending forming," China Mechanical Engineering, vol.26,pp. 1611-1615, January 2016.

[5] J.C. GU. "Machining technology of hardened steel mould for automotive large cover parts," Hot Material Report, vol.2, pp. 143-146, August 2015.

[6] Y.M. FU. "Key technologies and research progress of cooling system for injection moulds," Journal of Yanshan University, vol.31, pp.95-102, May 2017.

[7] X.L. WANG. "Application of digital technology in design and manufacture of stamping dies," Science and Technology Perspective, vol.22, pp. 268-268, June 2014. 